\title{
Partisipasi Masyarakat Dalam Musrembang Di Desa Bulo Kecematan Panca Rijang Kabupaten Sidenreng Rappang
}

\author{
Muh. Yusril Nurdin \\ Prodi Administrasi Publik. Fakultas Ilmu Sosial Dan Politik \\ Universitas Muhammadiyah Sidenreng Rappang \\ Email : Muhammadyusrilnurdin11@gmail.com
}

\begin{abstract}
ABSTRAK:
Tujuan penelitian untuk mengetahui partisipasi masyarakat desa dalam penyusuan rencana pembangunan desa Pajalele dapat menjadi salah satu tolak ukur sejauh mana desa tersebut mengembangkan nilai-nilai tata kelola pemerintahan desa yang baik dalam roda pemerintahanya. Partisipasi masyarakat dalam Musyawarah Perencanaan Pembangunan (Musrenbang) di Desa Bulo Kecamatan panca rijang Kabupaten Sidenreng Rappang. Jenis pengumpulan data ini adalah metode deskriptif dengan pendekatan kualitatif. Populasi penelitian ini adalah seluruh masyarakat di Desa Bulo Kecamatan panca rijang Kabupaten Sidenreng Rappang dan sampel yaitu masyarakat yang dianggap banyak mengetahui terhadap masalah yang dihadapi dan diharapkan agar responden yang dipilih mewakili populasi yaitu 80 orang. Penelitihan ini menunjukkan bahwa Pastisipasi Musyawarah Dalam Perencanaan Pembangunan (Musrenbang) di Desa Bulo Kecamatan Panca Rijang Kabupaten Sidenreng Rappang berada pada kategori baik, partisipasi masyarakat dalam musyawarah perencanaan pembangunan berada pada kategori sangat baik, dan Faktor-faktor yang mempengaruhi peranan pemerintah desa dan partisipasi masyarakat dalam Musyawarah Perencanaan Pembangunan berada pada kategori baik
\end{abstract}

Kata Kunci : Partisipasi Masyarakat;Musrenbang 


\begin{abstract}
The purpose of the study to determine the participation of the village community in the preparation of the Pajalele village development plan can be one of the benchmarks for the extent to which the village develops the values of good village governance in the wheels of government. Community participation in the Development Planning Deliberation (Musrenbang) in Bulo Village, panca Rijang District, Sidenreng Rappang Regency. This type of data collection is a descriptive method with a qualitative approach. The population of this research is the entire community in Bulo Village, Panca rijang District, Sidenreng Rappang Regency and the sample is people who are considered to know a lot about the problems they are facing and it is hoped that the selected respondents represent the population of 80 people. This research shows that Participation of Deliberations in Development Planning (Musrenbang) in bulo Village, Panca Rijang District, Sidenreng Rappang Regency is in the good category, community participation in development planning deliberation is in the very good category, and the factors that influence the role of village government and community participation in the Development Planning Deliberation is in the good category.
\end{abstract}

\title{
Keywords: Community Participation; Musrenbang
}

\section{PENDAHULUAN}

Melayani masyarakat dengan baik adalah merupakan tanggung jawab bagi semua pegawai. Dengan demikian maka setiap pegawai harus melayani masyarakat dan mempelajari cara meningkatkan keterampilan untuk melayani. Di dalam keterampilan melayani, termasuk pula di dalamnya adalah penguasaan terhadap pengetahuan jasa layanan yang diberikan, karena hal ini akan menunjukan kepada masyarakat bahwa pegawai tersebut adalah seorang profesional di bidang Manajemen Pelayanan Publik. Seorang profesional dalam dunia pelayanan publik seharusnya menguasai kebutuhan masyarakat, mengetahui cara memuaskan dan memenuhi kebutuhan masyarakat. Berdasarkan observasi yang ditemui di Desa Bulo sebagian dari pegawai 
masih kurang memahami, melayani, dan menghargai berbagai orang yang dijumpai setiap hari(Yenni Jamal, Ahmad Mustanir, 2020).

Beranjak dari hasil observasi, penulis tertarik untuk lebih jauh meneliti, menganalisis dan mengetahui lebih dekat tentang Penerapan Prinsip Good governance dalam pemerintahaan desa sehingga penulis mengangkat judul "Penerapan Prinsip Good Governance Terhadap Aparatur Desa Dalam Pelayanan Publik Di Desa Bulo Kecamatan Panca Rijang Kabupaten Sidenreng Rappang”(Yenni Jamal, Ahmad Mustanir, 2020).

Perencanaan pembangunan adalah proses pengembangan kapasitas masyarakat dalam jangka panjang sehingga memerlukan perencanaan yang tepat dan akurat. Perencanaan ini harus mampu mencakup kapan, di mana dan bagaimana pembangunan harus dilakukan agar mampu mendorong pertumbuhan ekonomi dan sosial secara berkesinambungan. Pemerintah daerah punya kewenangan yang lebih dalam perencanaan, pengelolaan anggaran dan pelaksanaan pembangunan. Artinya terjadi perubahan paradigma sistem pemerintahan, baik ditingkat pusat, provinsi, dan daerah(Mustanir \& Abadi, 2017).

\section{TINJAUAN PUSTAKA}

\section{- Konsep Partisipasi Masyarakat}

Konsep implementasi kebijakan merupakan suatu konsep yang memiliki berbagai perspektif yang berbeda-beda sehingga cukup sulit untuk merumuskan batasannya secara definitif. Dalam kamus Webster Wahab, (2005) pengertian implementasi dirumuskan secara pendek, dimana "to implementation" (mengimplementasikan) berarti "to provide means for carrying out (menyediakan untuk melakukan sesuatu); to give practical effect to" (menimbulakan dampak/ akibat terhadap sesuatu). Beranjak dari rumusan implementasi tersebut dapat diperoleh gambaran bahwa "to implementation (mengimplementasikan) berkaitan dengan suatu aktifitas yang terlaksana melalui penyediaan sarana (misalnya: undang-undang, peraturan pemerintah, pedoman pelaksanaan, sumber daya dan lain-lain) sehingga dari aktifitas tersebuat akan menimbulkan dampak/ akibat terhadap sesuatu(Mustanir \& Darmiah, 2016). 
konsep teori good governance ini merupakan implementasi dari terciptanya pemerintahan yang baik dan bersih dan selanjutnya Conyers (1991: 154-155) mengemukakan bahwa adanya tiga alasan utama mengapa partispasi masyarakat dalam mengidentifikasi masalah mempunyai sifat yang sangat penting. Pertama, bahwa partisipasi masyarakat merupakan alat guna untuk memperoleh informasi mengenai kondisi, kebutuhan dan sikap masyaakat. Kedua, bahwa masyarakat akan mempercayai proyek atau program pembangunan jika merasa terlibat di dalam proses atau program pembangunan,kepercayaan semacam ini adalah penting apabila mempunyai tujuan agar dapat diterima oleh masyarakat setempat(Zhilviana Sulaeman, Ahmad Mustanir, 2019).

Huther dan Shah pada Sedarmayanti $(2012 ; 98)$ menyebarkan konsep component of governance quality index, yang meliputi : indeks partisipasi warga negara, indeks orientasi pemerintah, indeks pembangunan sosial, dan indeks manajemen ekonomi. Laboratorium Good governance Provinsi Kalimantan Selatan menyebarkan 2 matrix indeks good governance yang meruapakan output "perkawinan silang" antara prinsip- prinsip good governance dan gosip-gosip strategis.

Pemerintahan Desa adalah penyelenggaraan urusan pemerintahan oleh pemerintah desa dan Badan Permusyawaratan Desa dalam mengatur dan mengurus kepentingan masyarakat setempat berdasarkan asal-usul dan adat istiadat setempat yang diakui dan dihormati dalam sistem Pemerintahan Negara Kesatuan Republik Indonesia (A. Mustanir and Yasin 2018) (Mustanir, Ahmad; Barisan, Barisan; Hamid 2017)(Mustanir et al., 2018).

Menurut (Mustanir \& Abadi, Partisan A., 2017) terdapat beberapa pengertian dasar mengenai partisipasi masyarakat, di antaranya adalah sebagai berikut.

1) Partisipasi masyarakat adalah peran serta masyarakat dalam berbagai kegiatan individu, kelompok atau badan hukum yang timbul atas kehendak dan keinginan sendiri ditengah masyarakat, untuk berminat dan bergerak di penyelenggaraan penataan ruang (Barisan, Ramadhan, and Mustanir 2017) (A. Mustanir and Rusdi 2019).

2) Partisispasi masyarakat adalah keterlibatan masyarakat sesuai dengan hak dan kewajibannya sebagai obyek dan subjek pembangunan, keterlibatan dalam tahap 
pembangunan dimulai sejak tahap perencanaan sampai pengawasan berikut segala hak dan tanggun jawabnya (A. Mustanir 2016) (A. Mustanir, Justira, et al. 2018).

Whereas in Kanyuara, in District of Sidenreng Rappang, the involvement of community participation especially in deliberation of development plan is very low. It is indicated by a few numbers of residents who are invited and attend the deliberation. The last deliberation of development plan was only attended by the representatives of Gapoktan as group of farmers(Mustanir \& Abadi, Partisan A., 2017).

\section{- Musyawarah Rencana Pembangunan}

Dalam penyelenggaraan pembangunan desa diperlukan pengorganisa- sian yang mampu menggerakkan masyarakat untuk mampu berpartisipasi dalam melaksanakan pembangunan desa serta melaksanakan administrasi pembangunan desa. Dengan demikian diharapkan pembangunan dan pelaksanaan administrasi desa akan berjalan lebih baik, tidak hanya didasarkan pada tuntutan emosional yang sulit dipertanggungjawabkan kebenarannya. Hal ini mengisyarakatkan bahwa keikutsertaan masyarakat di dalam perencanaan pembangunan desa memang benar-benar sangat dibutuhkan untuk mensinkronkan rencana pembangunan desa yang akan dilaksanakan dengan apa yang dibutuhkan masyarakat dalam meningkatkan kehidupan dan penghidupannya di desa. Karena bila tidak demikian, bisa saja pembangunan tersebut tidak sesuai dengan kebutuhan masyarakat yang bersangkutan sehingga pembangunan yang dilaksanakan sia-sia belaka dan masyarakat sendiri pun akan bersifat apatis terhadap pelaksanaan perencanaan pembangunan desa(Mustanir et al., 2020).

Dengan adanya peran partisipasi masyarakat maka hasil dari pembangunan yang dilakukan nantinya diharapkan dapat sesuai dengan keinginan dan kebutuhan dari masyarakat. Pembangunan tidak pernah tercapai tujuannya jika selalu meninggalkan masyarakat, pembangunan akan dinilai berhasil jika pembangunan tersebut membawa sebuah perubahan kesejahteraan dalam masyarakat, sehingga proses pembangunan merupakan proses tawar menawar antar kebutuhan masyarakat dengan keinginan pemerintah. Oleh karena itu dalam pelaksanaan pembangunan partisipasi masyarakat merupakan hal yang sangat mempengaruhi keberhasilan proses pembangunan itu sendiri. 
Perencanaan pembangunan juga berlaku bagi negara-negara yang sedang berkembang, karena ada bebrapa faktor, yaitu karena kegagalan mekanisme pasar, ketidakpastian masa datang, untuk mengarahkan kegiatan pembangunan. Indonesia merupakan salah satu negara berkembang yang tak luput dengan mekanisme parencanaan pembangunan dengan adanya SPPN (system perencanaan pembangunan nasional) Undang-Undang Nomor 24 Tahun 2004. Yang mana perencanaan pembangunan bukan hanya dilakukan pada tingkat pusat namun pada tingkat daerah juga(Mustanir et al., 2020).

\section{METODE PENELITIAN}

Penelitian ini menggunakan metode deskriptif kualitatif. (Moleong, $2010: 3)$ Teknik pengumpulan data yang dilakukan adalah: melalui Penelitian Lapangan dengan cara observasi dan wawancara (Data Primer), Studi kepustakaan/library research (membaca buku, majalah, surat kabar, dokumen-dokumen, dan media informasi lain dan Penelusuran data online yakni menggunakan fasilitas internet (Data Sekunder). Untuk mendapatkan hasil yang obyektif dalam penelitian ini, maka data yang didapatkan dilapangan akan diolah dan dianalisa secara kualitatif, yaitu dengan menggambarkan dan menjelaskan hasil-hasil penelitian dari sejumlah data-data yang telah diperoleh.

\section{PEMBAHASAN}

Indonesia dewasa ini di mana masyarakatnya sudah semakin kritis, maka yang diperlukan adalah dakwah yang berorientasi pada transformasi global dan yang bisa menerima keadaan zaman serta kemajuan teknologi dalam kehidupan, baik melalui penyadaran, pendidikan, dialog, maupun ilmu pengetahuan agar mampu menjadi perubahan secara struktural atau kultural yang lebih baik. Salah satu persoalan krusial sebagai dampak proses globalisasi yang terkait dengan kehidupan keagamaan adalah makin menepisnya ruang religiusitas dalam konteks kehidupan manusia (Istina Rakhmawati: 2014). Keadaan ini menyebabkan waktu personal masyarakat tidak lagi banyak kesempatan memasuki tempat-tempat peribadatan seperti masjid. Lantas apakah sasaran dakwah hanya ditujukan bagi mereka yang memasuki tempat ibadah saja. Tentu tidak, dalam situasi 
apapun dan dimanapun manusia bisa menjadi obyek dan subyek dakwah. Strategi dakwah Islamiyah seharusnya tidak semata- mata berorientasi pada kesemarakan tempat tertentu tetapi justru banyak diarahkan pada pendalaman dan pengembangan wawasan keislaman demi siarnya Islam(Mustanir \& Rusdi, 2018).

Paling penting dalam setiap partisipasi masyarakat adalah bagaimana mereka berpartisipasi atau turut serta secara langsung dalam tentunya sangat berpengaruh. setiap kegiatan yang dilakukan karena dalam suatu kegiatan dapat dikatakan berhasil jika masyarakat tertarik dan ikut serta dalam kegiatan tersebut. Dengan banyaknya masyarakat yang ikut berpartisipasi dapat dikatakan bahwa manajemen pengelolaan dalam kegiatan tersebut berhasil dikarenakan dapat menarik minat masyarakat. Karena masyarakat dikalangan sekarangan ini mereka sibuk dengan pekerjaannya masing-masing sehingga kurang berpartisipasi ketika ada kegiatan yang dilakukan baik dipemerintah desa maupun di Badan Usaha Milik Desa tersebut(P, Monalisa Ibrahim, Ahmad Mustanir, 2020).

Adisasmita dalam (Sapri et al., 2019)(Adam Latif, Irwan, 2019) mengemukakan jenis partisipasi terdiri:

a) Partisipasi uang/harta benda yaitu partisipasi dalam memberikan harta benda atau uang.

b) Partisipasi tenaga yaitu memberikan sumbangsih tenaga fisik dalam pelaksanaan kegiatan. Partisipasi keterampilan adalah memberikan keahlian yang dimiliki kepada masyarakat lainnya yang membutuhkan.

c) Partisipasi ide pikiran adalah partisipasi berupa sumbangan pikiran, pendapat yang konstruktif dalam memperlancar pelaksanaan program dan mengembangkannya.

d) Partisipasi didalam pengambilan kebijakan, dimana masyarakat terlibat dalam setiap kegiatan pengambilan kebijakan yang ada kaitannya dengan kepentingan bersama.

Partisipasi dimaknai yaitu "partisipasi masyarakat adalah keikutsertaan masyarakat untuk mengakomodasikan kepentingan mereka dalam proses penyusunan rencana pembangunan" Dari pengertian di atas dapat disimpulkan bahwa partisipasi masyarakat merupakan keterlibatan atau keikutsertaan seseorang masyarakat dalam proses interaksi sosial, pengidentifikasian masalah dan 
potensi yang ada di masyarakat dalam situasi tertentu, baik dalam pengambilan keputusan (solusi) menangani masalah, pelaksanaan upaya mengatasi masalah, dan proses keterlibatan masyarakat di dalam mengevaluasi perubahan yang terjadi. Dari definisi ini penulis melihat bahwa keterlibatan partisipasi masyarakat yang rendah di Kelurahan Kanyuara dapat mengakibatkan perencanaan pembangunan melalui musrenbang tidak dapat mencapai hasil yang maksimal.

Partisipasi sepadan dengan arti peranserta, ikutserta, keterlibatan, atau proses belajar bersama saling memahami, menganalisis, merencanakan dan melakukan tindakan oleh sejumlah anggota masyarakat. Penggalangan partisipasi itu dilandasi adanya pengertian bersama dan adanya pengertian tersebut adalah karena diantara orang-orang itu saling berkomunikasi dan berinteraksi sesamanya. Dalam menggalang peran serta semua pihak itu diperlukan (1) terciptanya suasana yang bebas atau demokratis dan (2) terbinanya kebersamaan. Selanjutnya dinyatakan bahwa, partisipasi masyarakat dalam pembangunan adalah sebagai ikut sertanya masyarakat dalam pembangunan, ikut dalam kegiatan-kegiatan pembangunan, dan ikut serta memanfaatkan dan menikmati hasil-hasil pembangunan7.

Masyarakat mengandung pengertian suatu keseluruhan kompleks hubungan manusia yang sangat luas sifatnya. Masyarakat adalah kesatuan hidup manusia yang berinteraksi menurut suatu sistem adat istiadat tertentu yang bersifat kontinyu dan terikat oleh rasa identitas bersama10. Masyarakat adalah golongan besar atau kecil yang terdiri dari beberapa manusia yang dengan sendirinya bertalian secara golongan dan mempengaruhi satu sama lain. Saling mempengaruhi artinya pengaruh dan pertalian kebathinan yang terjadi dengan sendirinya yang menjadi unsur yang harus ada bagi masyarakat. Masyarakat bukan berarti penjumlahan orang-orang saja, tetapi diantara mereka harus ada pertalian satu sama lainnya yang merupakan kesatuan yang selalu berubah yang hidup karena proses dan menyebabkan perubahan dapat terjadi dalam kehidupan manusia.

\section{REFERENSI}


Adam Latif, Irwan, A. Mustanir. (2019). Analisis Kepemimpinan Terhadap Optimalisasi Masyarakat Pada Perencanaan Pembangunan Di Enrekang. Analisis Kebijakan Dan Pelayanan Publik, 5(2), 1-20. https://doi.org/10.20956/xxxxxx

Mustanir, A., \& Abadi, Partisan A., N. (2017). Participation of Ethnic Community Towani Tolotang in Deliberation of Development Plan. 84(Iconeg 2016), 356-359. https://doi.org/10.2991/iconeg-16.2017.79

Mustanir, A., \& Abadi, P. (2017). Partisipasi Masyarakat Dalam Musyawarah Rencana Pembangunan Di Kelurahan Kanyuara Kecamatan Watang Sidenreng Kabupaten Sidenreng Rappang. Jurnal Politik Profetik, 5(2), 247-261. http://journal.uinalauddin.ac.id/index.php/jpp/article/viewFile/4347/3986\%0Ahttp://journal.uinalauddin.ac.id/index.php/jpp/issue/view/636

Mustanir, A., \& Darmiah, D. (2016). Implementasi Kebijakan Dana Desa Dan Partisipasi Masyarakat Dalam Pembangunan Di Desa Teteaji Kecamatan Tellu Limpoe Kabupaten Sidenreng Rappang. Jurnal Politik Profetik, 4(2), 225-238. http://journal.uinalauddin.ac.id/index.php/jpp/article/view/2749\%0Ahttp://journal.uinalauddin.ac.id/index.php/jpp/issue/view/457

Mustanir, A., Fitriani, S., Adri, K., Nurnawati, A. A., \& Goso, G. (2020). Sinergitas Peran Pemerintah Desa dan Partisipasi Masyarakat Terhadap Perencanaan Pembangunan di Kabupaten Sidenreng Rappang (The Synergy of Village Government's Role and Community Participation in the Process of Development Planning in Sidenreng Rappang D. Journal of Government Science (GovSci), 2020, 1(2): 84-108, 2020(2), 84-108.

Mustanir, A., Kamarudding, S., Akhwan, A., Madaling, \& Mutmainna. (2018). Peranan Aparatur Pemerintahan Desa dan Partisipasi Masyarakat Dalam Musyawarah Perencanaan Pembangunan di Desa Tonrongnge Kecamatan Baranti Kabupaten Sidenreng Rappang. Jurnal Ilmiah Clean Government, 2(Desember), 67-84.

http://lonsuit.unismuhluwuk.ac.id/index.php/clean/article/view/213

Mustanir, A., \& Rusdi, M. (2018). Participatory Rural Appraisal (PRA) Sebagai Sarana Dakwah Muhammadiyah Pada Perencanaan Pembangunan di Kabupaten Sidenreng Rappang. 
Prosiding Konferensi Nasional Ke-8 Asosiasi Program Pascasarjana Perguruan Tinggi Muhammadiyah Aisyiyah (APPPTMA), 8(3 Des), 467-475.

$\mathrm{http}$ ://asosiasipascaptm.or.id/index.php/publikasi/prosiding-konferensi-nasional-appptma-ke $-8$

P, Monalisa Ibrahim, Ahmad Mustanir, A. A. A. N. A. (2020). Pengaruh Manajemen Pengelolaan Badan Usaha Milik Desa Terhadap Peningkatan Partisipasi Masyarakat Di Desa Bila Riase Kecamatan Pitu Riase Kebupaten Sidenreng Rappang. Movere Journal, 2(2), 56-62. https://doi.org/10.53654/mv.v2i2.118

Yenni Jamal, Ahmad Mustanir, A. L. (2020). Penerapan Prinsip Good Governance Terhadap Aparatur Desa Dalam Pelayanan Publik Di Desa Ciro-Ciroe Kecamatan Watang Pulu Kabupaten Sidenreng Rappang. PRAJA: Jurnal Ilmiah Pemerintahan, 8(3), 207-212. https://doi.org/10.51817/prj.v8i3.298

Zhilviana Sulaeman, Ahmad Mustanir, A. I. M. (2019). Partisipasi Masyarakat Terhadap Perwujudan Good Governance Di Desa Damai Kecamatan Watang Sidenreng Kabupaten Sidenreng Rappang. PRAJA: Jurnal Ilmiah Pemerintahan, 7(3), 88-92. https://doi.org/10.51817/prj.v7i3.374 